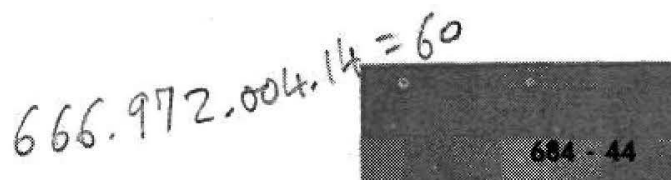

\title{
el hormigón pesado y su utilidad incustrial
}

le béton lourd et son utilite industrielle

(«L'Usine Nouvelle», núm. 46, pág. 95, noviembre do 1959.)

El hormigón pesado es conocido desde hace largo tiempo, pero no se ha considerado útil hasta hace algunos anos. Su empleo no tenía justificación, particularmente en la construcción, donde siempre se busca su ligereza.

Su necesidad ha sido reconocida con el nacimiento de la energia atómica. Esta planteó problemas humanos de protección contra las radiaciones, las cuales son absorbidas por una masa que debe ser de dimensiones muy reducidas por razones técnicas de obra, de obstrucción, de superestructura y de manipulación.

El hormigón pesado de protección biológica es, generalmente, fijo; pero puede ser móvil: puertas sobre correderas, bloques levadizos, ladrillos...

Desde el campo nuclear, el hormigón pesado ha pasado al dominio industrial: lastre fijo o móvil, contrapesos, tensores de cables, etc...

Al ser considerable el precio de coste, estudiaremos los materiales pesados menos caros y de fácil colocación en obra, en particular la baritina.

\section{Elección del árido}

Esta elección queda definida por la densidad requerida. La conjugación de las variables peso y precio elimina los metales pesados caros, ya que deben ser trabajados para obtener un buen coeficiente volumétrico.

El plomo, los aceros $\mathrm{y}$ sus desechos (desengrasados), la fundíción, la magnetita rica, forman excelentes áridos si están bien preparados (es preciso eliminar absolutamente todas las virutas de torno, pernos, tuercas, etc.); pero éstos son materiales difíciles de encontrar en grandes cantidades o bien proceden de largas distancias, o bien son objeto de especulaciones con posible escasez en ciertas épocas.

Entre estos áridos y las arenas y gravas de río existe la baritina, que resulta favorable en el compromiso de peso y precio.

\section{La baritina}

La baritina, sulfato de barita, o más exactamente sulfato bárico ( $\left.\mathrm{SO}_{4} \mathrm{Ba}\right)$, es un mineral que se halla en estado más o menos puro en la naturaleza. En los yacimientos, la baritina se presenta en forma de flones casi verticales, y la extracción (por galerías subterráneas) se hace, bien síguiendo el filón, o bien en sentído normal a los lechos.

La baritina extraída se tritura, se lava, se valora y se enriquece gravimétricamente.

El peso especifico del mineral es 4,50, pero su densidad práctica aproximada es 4,20. Su pH es 7 . Y no ofrece, en absoluto, ningún inconveniente para su empleo, a causa de su inercia química total; es insensible a la acción del hielo.

Sus usos comerciales no son nuevos. Si en otros tiempos, los Antiguos (galo-romanos) buscaron los metales despreciando la baritina, hoy se busca por sí misma: en la industria química, cuando está muy bien molida, se emplea como carga en las pinturas, caoutchoucs, cartonajes, etc. (litopón, por ejemplo). Las sociedades de exploración y de explotación petroliferas hacen más pesados sus barros de perforación con el sulfato de barita.

El consumo mundial total ha sido de unos tres millones de toneladas métricas en el año 1958 .

\section{Elaboración del hormigón}

Las granulometrías a emplear son función del espesor del blindaje de protección o de la forma o dimensión del contrapeso, por ejemplo.

Para el hormigón normal, es corriente emplear una granulometría discontinua con arena y grava. Para el hormigón pesado se recomienda, si ésta es continua, estudiar previamente la granulometría, que da mejores resultados.

Hay una gama de tamafíos bastante extensa: $0 / 3,3 / 8,8 / 15,15 / 30$, e incluso $30 / 80 \mathrm{~mm}$, sil la obra tiene dimensiones importantes. 
Se recomienda siempre utilizar una barițina ex ənta de ópalo, calcedonia, particulas terrosas u orgánicas, y de todas aquellas sustanclas quimicas que pueden atacar el cemento o el hierro de las armaduras.

El hormigón pesado baritico es fácil de colocar siempre que se tomen algunas precauciones: el encofrado debe ser reforzado (eventualmente se usa encofrado metalico que puede quedar como perdido).

La resistencia a la compreslón es de unos $350 \mathrm{~kg} / \mathrm{cm}^{2}$ y a la tracción de $30 \mathrm{~kg} / \mathrm{cm}^{2}$. La resistencia mecánica de la baritina, y, en consecuencia, la del hormigón, es proporcional a su cohesión; la cohesín de la baritina es inversamente proporcional a su pureza. De forma que se tendrá cierto interés práctico el empleo de baritinas químicamente menos puras, pero que ofrezcan una mayor dureza. Durante la puesta en obra no se alteran las granulometrias.

Una baritina del análisis que se da a continuación resulta muy satisfactoria:

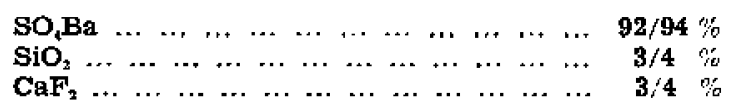

La silice inclúdá da cohesión. Ed fluoruro cálcico no perjudica: como sabemos, las fábricas de cemento lo incorporan en sus crudos.

\section{Composición granulométrica tipo:}

En peso:

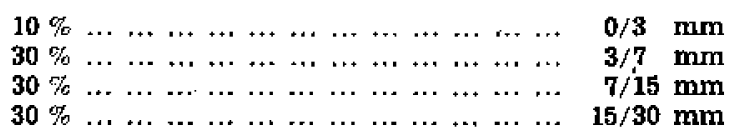

Sì se fabrican pequeños bloques no deben superarse los $15 \mathrm{~mm}$.

El hormigón debe prepararse lo más seco posible: 130 litros de agua por metro cúblco, $y$, la dosiflcación en cemento lo más pobre admistble: 300 a $350 \mathrm{~kg}$ por metro cúbico.

\section{Resulfados de densidad}

El hormígón obtenido después de vibración o pervibración tiene una densidad de 3,$70 ; y$ sł es un hormigón seco, posee, al cabo de algunos dias, una densidad minima de 3,60 .

\section{Hormigón mixto}

Puede ser que la densidad 3,60 sea insuficiente. En este caso, es corriente 1ncorporar a la mezcla granatla de hierro o fundiclón, o bolas de acero, esto resulta caro g puede provocar la segregación.

\section{Ventajas}

Ė hormigón barítico es fácil de enmoldar o perforar (lo que no ocurre con un hormigón a base de chatarra).

Su poco valor impide Ios peligros del robo, como en el caso de los metales.

\section{Usos industriales}

Independientemente de las construcciones nucleares, desde hace algún tiempo aparecen continuamente nuevas salidas industriales para los hormigones pesados prefabricados: lastre fljo o móvil para barcos, camiones, grúas, palas mecánicas; toda clase de contrapesos para ascensores, puertas basculantes, barreras de entrada en fábricas, mesas de dibujo, tensores de cables, pies para postes indicadores intoovites, ples de sombrillas, ples de lámparas, cuerpos muertos, etc.

Slendo la acumulación de calor proporcional a la densidad, se están haciendo estudios para el empleo de la baritina en la construcción (edificación): calefacción por el suelo y revestimientos murales.

Se efectuan trabajos corrientes con la baritina para la protección contra rayos $X$, en las salas de radiologia en los hospltales, gabinetes médicos, laboratorios. En Ia actualidad, se hacen numerosas y nuevas instalaciones para las bombas de cobalto (anti-cáncer).

Las protecciones mal conocidas fueron objeto da estudio entre las dos guerras, y sólo ha sido recientemente cuando se han creado e impuesto normas.

Estas protecciones técnlcas entrarán, sin duda alguna, próxlmamente en el cuadro de la protección civil (refugto obligatorio para toda nueva construceión en sujza, por ejemplo).

Como el hormigón con barita, después de pulido, parece un mármol, la estética y lo útil no pueden por menos que unirse en una época donde hay tendencla al embellecimiento. 